\title{
America's Health in Two Centuries
}

\section{E. J. McClendon, EdD}

This is Dr. McClendon's response upon receiving the William A. Howe Award, the highest honor conferred by the American School Health Association, which was presented at the 50th Anniversary Convention, October 9, 1976.

It seems appropriate that on the occasion of the golden anniversary of the American School Health Association and the 200th anniversary of our nation we take a look at health care 200 years ago and 50 years ago. The signal improvements in mankind's understanding of the body, of disease, of disease-causing organisms and conditions, and the treatment and prevention of these are so dramatic that they test credibility of our recording. It seems improbable, almost impossible, that so much could have happened in so short a time span.

Some wag has said, "Don't look back unless you plan to go that way." There is, however, at least two good reasons to look at the past: one is to help us better understand the present, and the other is to provide a basis for projecting into the future. Winston Churchill said, "If we open a debate between the past and the present, we shall find that we have lost the future." The purpose then, of this brief inquiry into the past, is to know where we have been as a means of assessing our present and charting our future.

Recounting our health quotient at the time of the nation's birth may easily become a litany of what we did not know, did not have, and could not manage. This paper is in no sense a comprehensive review of health conditions circa 1776. It merely proposes to take some samples of the health problems of the time, which may be displayed against the common knowledge of the present for contrast.

Vaccination for any disease, as we know it, did not exist in 1776. Edward Jenner was working on his idea for using a strain of cowpox to inoculate against smallpox at that time. Benjamin Franklin was among those in this country who advocated inoculation or intentional infection, with material from a pox as a form of preventive smallpox infection. He kept records on some cases using this type of inoculation and found those inoculated had a higher survival rate than did persons who just contracted the disease. That may have been the first epidemiologic study in America.

At the time of the revolution some of the most basic tools of medicine did not exist. Laennec would not invent the stethoscope until 1815-as a matter of fact, he wasn't born until six years after the Declaration of Independence. There was no anesthetic; surgery was performed by having two strong men hold the patient.

Louis Pasteur would not confirm the postulate about microorganisms as the cause of disease until the time of the American Civil War; Lister's thesis on antiseptic surgery was being debated as the US approached the celebration of its first 100 years.

While an Italian scientist, Giralamo Frascatoro or Frascatorius, who named syphilis, advanced a proposition on the process of infection and disease transmissability in 1546 , it took over 100 years for the development of the microscope and another 100 years of study to begin to support his belief. Jean Astruc (or John Astre), the personal physician to King Louis XIV of France, in a treatise on venereal disease in 1754, wrote "A certain quack whose name was Boule, maintained that all diseases are caused by little animals (animalcula) in the blood and different diseases by different little animals (animalcula) and that there were other animals which were capital enemies of these noxious (little) animals by which they were capable of being purified." From this we may infer that the world's knowledge of scientific medicine was in a very primitive state. Thus, the American Colonies had little to "borrow from."

Looking again at America, the colonies do not appear to have been lead by persons who exuded kindness or humanitarianism, as an expression of good mental health. The Salem witch trials are well known. They (the witches) were charged among other things with responsibility for an epidemic. It was commonplace to blame illness on blasphemy, the wrath of God, or witchcraft. General Jeffry Amherst, in command of British forces in America 
during the French and Indian war and later commander-in-chief of the entire British army during the American Revolution, received a letter in 1732 from one of his subordinates advocating the use of specially trained dogs to hunt down Indians. In reply, he wrote, "You will do well to try to inoculate the Indians by means of blankets in which smallpox patients have slept, as well as by every other means that can serve to extirpate this excreable race. I should be very glad if your scheme of hunting them down by dogs could take effect."

Two medical leaders of the time were Benjamin Franklin, often called Doctor Franklin because he was a scholar, not a physician, and Dr Benjamin Rush. Rush was a prominent physician, who along with Franklin was a signer of the Declaration of Independence. Among Franklin's contributions to health matters were: his theory of lead as a cause of poisoning; his help in founding one of the first hospitals and medical schools; his invention of bifocal glasses and his strong advocacy of personal hygiene and of ventilation of living spaces. Dr Rush, who wrote a classic treatise on alcoholism in 1785, was Surgeon General of the Continental Army and is generally recognized as the foremost physician of his time.

There was an outbreak of yellow fever in Philadelphia during the time the Declaration of Independence was being drafted. It is a marvel that the fever did not decimate the delegates to the Continental Congress. Since most of the cases of fever were found near the waterfront, it was debated by physicians as to whether the cause was garbage thrown into the river or piles of rotting rope left on the docks. The insignificant little mosquito was apparently never suspect.

Perhaps nothing was more constraining to the development of modern medicine than some of the religious dogmas of the day. Medical research had to be descriptive, not experimental, since it was thought "immoral to experiment with God's creatures." As late as 1845 the prestigious publication The Scientific American carried an article on rational religion, which said, "Rational scientific thought must acknowledge God as our creator and preserver," and it went further to say that keeping us alive and well could only be attributed to divine power in face of all the ills that may beset us.

The improvement in infant survival rates in the US in the past 200 years may be the most dramatic evidence of the enhanced quality of health care. An infant born in 1776 had only a $50 \%$ chance of living to reach age 21 ; today that child has a $97 \%$ chance to survive to that age.
The dissemination of information on health was also poor. Dr Harvey's treatise on blood was written in 1628, yet bleeding was a common form of treatment used by physicians for a variety of illnesses at the time of the revolution, as was the use of purgatives.

The death of George Washington, probably the most honored man of his time, gives a classic view of medical care of that era. He died of quinseyan acute form of tonsilitis. His physicians bled and purged him several times the night before his death. They were debating doing a tracheotomy, which had never been done before in this country, when he overheard them and said, "I prefer it not-I choose not to be an experimental study-I sense the end is near now and would go peacefully."

Folk medicine was common place and often nearly as effective as that rendered by the medical community. Most treatment of the ill was of the home-made, superstition borne, variety. Poultices were used for everything, purgatives were a common remedy, broken bones were often not set, bile in the stomach was considered an undesirable condition requiring treatment, and regurgitation of soured milk was considered evidence of digestive failure.

One might say of the state of medicine, medical knowledge, and medical care in the colonies, "If you didn't die of the treatment-you had a good chance to survive the disease."

One can hardly help being impressed with the changes and improvements in health care that have come in the 200-year history of our nation; but one may be even more impressed with how many of those "breakthroughs" have come within the 50-year life span of our own School Health Association.

Looking back to 1926 it may be said that we were indeed entering the scientific era in medicine and public health in America. Diphtheria was still a dreaded threat to children at the time and immunization programs were not provided to, or accepted by, large segments of the population. Looking at death rates, heart disease and stroke, then as today, headed the list followed by cancer; but lobar pneumonia and tuberculosis still followed close behind.

Consider that there were no National Foundation for Infantile Paralysis and, of course, no polio vaccine. Tuberculosis was a scourge with the national death rate above 50 per 100,000 population, even allowing for what were probably incomplete statistics, and there were no TB drugs. Penicillin was not discovered and two decades would pass before 
it came into common use. Cancer control would not be recognized as a public health problem for almost 20 years and the pertussis (or whooping cough) vaccine would not be perfected for 15 years. The World Health Organization would not be created for more than 20 years.

There were, however, some positive forces at work at the time. The National TB Association (now the American Lung Association), the first major national voluntary health agency, had taken a strong position in support of school health; the National Society for Crippled Children and Adults was five years old and growing, and a Public Health Education Section had been organized within the American Public Health Association. In 1918 two significant events occurred: the National Commission on Reorganization of Secondary Education identified health as the first of the seven cardinal principles of education, and the Child Health Organization of America was founded. Also in 1920 Dr Thomas Wood released the third edition of his report, "Minimum Health Requirements for Rural Schools," under the auspices of the Joint Committee on Health Problems in Education of the NEA and the AMA (which had been founded in 1911), and the National Congress of PTA began sponsoring the summer round-up campaigns in 1925. These may well have foretold the need for and pointed to the coming of the American School Health Association.

The concept of federal-state related health services for children, however, was still to come, as was the movement to clean-up milk supplies, which were shown to be a source of spreading childhood diseases. Good prenatal health care programs for pregnant women, as a means to healthier children, as well as an understanding of the significant impact of nutritional deficiencies on the health of the young were still in the future. Health education was conceived of as a system for giving people health facts. The value of fluorides in preventing tooth decay was unknown and the nutrition sciences were essentially undeveloped. Federally supported school lunch programs did not exist. Smallpox was still a serious disease threat and there was resistance to immunization against it on many fronts. Laws requiring premarital blood tests for discovery of syphilis were not yet enacted.

The National Conference on Cooperation in Health Education would not be formed for another dozen years. The question of whether government had any proper role in the treatment of the ill was still being widely debated; however, quarrantine for control of communicable disease outbreaks was standard procedure. J. Arthur Myers and his group had not even begun their program to certify schools as protected against tuberculosis.

This brief look across these last 50 years prompts the conclusion that the explosions of knowledge and of the evolution of techniques in the health sciences have almost outrun the reaches of the mind. On the other hand it appears that education for health decision making and for self directedness about health matters has progressed much more slowly, in some ways almost not at all.

The era of communicable diseases is behind us, with the exception of the venereal diseases, where the problem is educational not clinical. The health challenges of the future are ecologically and socially based. Cancer is surely linked to environmental factors; child abuse makes us cry out that every child must be wanted, protected, fed, educated and loved; family planning and prenatal care are needed to reduce the number of high risk infants and the incidence of birth defects. Life style, stress, diet, exercise, health care priorities and personal health choices, all are matters we can control individually or collectively. Alcohol dependency, drug abuse, mental health problems, coping skills, low selfesteem, family conflict and problems of parenting are social issues, but they are also the real health problems of the present. For the geriatric person, it is not enough to live longer, just to exist, the quality of living must be enhanced. These are the source and the prototype of the health problems of today and tomorrow. As the staggering rate of change continues and increases, the American School Health Association is not without the ingenuity and intellectual resources to attack these and those unforeseen health issues of the future. ASHA eagerly awaits the next 50 years.

\section{BIBLIOGRAPHY}

Bowman R: Some significant events in the history of community health education. Unpublished report, University of Michigan School of Public Health, 1974.

Child health in America. Public Health Reports $91: 289$ $290,1976$.

Edwards R: Health and medical care at the time of the American centennial. $J$ Sch Health 46:77-80, 1976.

Henkel BO: Community Health, ed 2. Boston, Allyn and Bacon, 1970 , p 90.

Marks G, Beatty WK: Story of Medicine in America. New York, Charles Scribner's Sons, 1973.

Means RK: Historical Perspective on School Health. Thorofare, NJ, Charles B. Slack, 1975.

Medicine. Time: Special Bicentennial Issue. 107:48, Sept 26,1789 .

Moquin W, Van Doren C (eds): Great Documents in American Indian History. New York, Praeger, 1972.

Michigan Department of Public Health: First One Hundred Years. Lansing, Mich, 1973. 
Rational religion. Scientific Amer I:3, Aug 28, 1845.

Rush B: An alcoholism classic: Excerpts from "An inquiry into the effects of ardent spirits on the human body and mind." Alcohol Health and Research World. Dept HEW, National Institute on Alcohol Abuse and Alcoholism, 1976, pp 7-9.

Seven cardinal principles revisited: A bicentennial project. Today's Educ 65:57-72, 1976.
University of Michigan Papers, Research News, Division of Research Development, University of Michigan. 27: 4-5, 1976.

E. J. McClendon, EdD, is Professor and Chairperson, Health Education, School of Education, and Associate Professor, School of Public Health, University of Michigan, Ann Arbor, MI 48109.

\section{Birth Defect Information Available Through Computer System}

A worldwide computer system to provide physicians with rapid diagnostic information about known birth defects has been developed in a joint effort by The National Founda. tion-March of Dimes, Tufts-New England Medical Center, and the Massachusetts Institute of Technology.

A team of physicians and computer scientists are now conducting clinical trials of the system, which will help doctors everywhere to identify rare birth defect syndromes and alert them to unusual patterns in the occurrence of congenital disorders. The system is expected to be fully operational after a six-month test period.

The development and testing team is led by Daniel Bergsma, MD, vice president for professional education for The National Foundation; Sydney S. Gellis, MD, pediatrician-in-chief, Tufts-New England Medical Center; and Professor John J. Donovan at the MIT Sloan School of Management.

"There are approximately 1400 known birth defects," Dr Bergsma says. "Many are so rare that a practicing physician may not see even one case in his entire career."

The computer will enable a physician to submit his patient's signs and symptoms to the information system. In seconds, the computer can request additional in formation, display diagnostic possibilities, and supply other useful information on request, such as the probability of recurrence in future offspring.

Available 24 hours a day, the computer will be hooked into the public telephone system, enabling physicians to dial the central processing unit from almost any computer terminal in any local hospital or other facility, transmit pertinent information about a patient with a birth defect, and read responses displayed on the local terminal.

Information collected, analyzed and then provided by the computer may one day prevent another tragedy similar to the thalidomide disaster by alerting professionals to an increase in certain birth defects, giving them valuable extra time to trace causes before many children are affected.

"The computer stores updated genetic and birth defects data continually," Professor Donovan says. "There are al. ready some 45 new facts entered each week. This provides a constantly updated body of information that is immediately available to the medical community."

The system has multiple uses, including: a Birth Defects Registry which will separately record syndromes which neither the computer nor expert physicians can yet identify as distinct birth defects; Clinical Aid to Diagnosis; Birth Defects Information Retrieval; Computer-Aided Instruction about Birth Defects; and the Early Warning System described above.

"The computer system will not only aid the practicing physician, but will also supplement medical centers of fering full diagnostic services and evaluation of genetic disorders," Dr Gellis says. "Such centers have great expertise in diagnosis of specific birth defects, but they too will greatly benefit from access to computerized data, especially in the area of rare and unusual defects. The computer will offer a rapid means of arriving at a diagnosis on a sound scientific basis." 